

BRAZILIAN JOURNAL

$\mathrm{OF}$

RADIATION SCIENCES

09-02A (2021) 01-13

\title{
Simulation of the burnup in cell calculation using the wimsd-5b code considering different nuclear data libraries
}

\author{
D. Y. S. Tavares ${ }^{1}$; A. C. da Silva ${ }^{1}$; Z. R. de Lima ${ }^{1}$; M. M. Martins ${ }^{2}$ \\ Instituto de Engenharia Nuclear CNEN, 21941-614, Rio de Janeiro, RJ, Brazil \\ Instituto de Radioproteção e Dosimetria CNEN, 22783-127, Rio de Janeiro, RJ, Brazil \\ zelmolima@yahoo.com.br
}

\begin{abstract}
This work proposes to implement the cell calculation considering the fuel burning using the wimsd- $5 \mathrm{~b}$ code. The cell calculation procedure allows determining the nuclear parameters present in the multi-group neutron diffusion equation and for this purpose the neutron transport theory is used in a problem with dimensional reduction, but in contrast is considered a large number of groups associated with the neutron spectrum. There are a variety of reactor physics codes that determine the nuclear parameters by solving the neutron transport equation applied to an equivalent cell representing a fuel element. The wimsd- $5 \mathrm{~b}$ code is a deterministic code that solves the transport equation using collision probability method. The simulation of fuel burning in the cell calculation took into account different nuclear data libraries. The wimsd- $5 \mathrm{~b}$ code supports several nuclear data libraries and, in the present, work the following libraries were used: IAEA, ENDFB-VII.1, JENDL3.2, JEFF3.1 and JEF2.2, all formatted for 69 energy groups. The simulation of the cell calculation using the wimsd-5b code helped to understand the fuel element burnup in nuclear reactor.
\end{abstract}

Keywords: cell or network calculation, wimsd-5b, fuel burnup.

\section{INTRODUCTION}

In a first analysis of a reactor core, there are computational implementations which consider the 
nucleus with infinite dimension, exploring repetitive geometry, and a high number of energy groups. These computational implementations are called cell or network calculation codes. These codes are used to determine the distribution of the neutron flux and the multiplication factor in an infinite medium. For this purpose, it is necessary to provide with input data from these codes the multi-group isotope nuclear data sets and also the description of the cell that repeats infinitely in the reactor, also known with equivalent cell.

The cell calculation codes solve the neutron transport equation over a specific region of the reactor: unit cell or macro-cell [1]. Therefore, cell calculation codes include methods to solve an appropriate set of equations for neutron flux and infinite multiplication factor, k $\infty$, considering discretized energy and a spatial network (energy groups and discretized spatial points). The calculated neutron flux can be used to obtain sets of homogenized macroscopic cross sections covering selected sub regions and in a broad energy group structure. These sets of macroscopic cross sections are then used as input material data for several codes that solve the neutron transport equation or the neutron diffusion equation over the entire reactor core or part thereof. The neutron flux thus calculated can then be used for the calculation of reaction rates or in fuel depletion calculations distributed over this effective nucleus.

Another important feature, which that is found in most cell calculation codes, is the ability to simulate burnup during the operation of the nuclear reactor, providing the concentrations of the various nuclides as well as the sets of macroscopic cross sections at each burnup step.

\section{2. wimsd-5b CODE}

The Winfrith Improve Multigroup Scheme (wims) is a deterministic code based on the transport theory to calculate the flux as a function of the energy and position in the cell, performing calculation for different geometries, providing the physical parameters necessary for the development of reactor designs nuclear weapons of various types. Since the 60's it has been successful in its results, in addition it is widely accepted internationally, being one of the most used in the management of core nuclear reactors. Its standard library has data from multi-group cross sections of the materials most commonly used in nuclear reactors. 
The code wimsd- $5 \mathrm{~b}$ uses the nuclear data libraries with the same structure of 69 energy groups of the original code, WIMS-D, with 14 fast groups between $9.118 \mathrm{keV}$ and $10 \mathrm{MeV}, 13$ groups of resonances between $4 \mathrm{eV}$ and $9.118 \mathrm{keV}$, and 42 thermal groups from $0 \mathrm{eV}$ to $4 \mathrm{eV}$.

More recently, with new updates, the code now has libraries with up to 172 power groups or more. Among the various available libraries may be cited the following: WDN29, ENDFB-VII.1, ENDFBVII.1GX, JENDL3.2, JENDL3.2GX, JEF2.2, JEF2.2GX, JEFF3.1, JEFF3.1GX, IAEA and IAEAGX [2]. The wimsd code develops the calculation of cells in four different geometries: homogeneous cells, cylindrical plates or bars, bar or plate arrays (cluster geometry) and multi-cells. In this work the calculation was made from the data of a one-dimensional cell (Slab).

Some of the most significant items produced by the calculations of this code are: the infinite multiplication factor, $\mathrm{k}_{\infty}$, the effective multiplication factor, if the leakage data, isotope reaction rates present in the calculation are reported, the mean constants and the final concentrations of the nuclides and fission products in cases of burning [3].

\subsection{Burning Calculation in wimsd-5b code}

In the wimsd code the burning equation for each material and isotope $i$ is written as follows:

$$
\frac{d N_{i}(t)}{d t}=-\left(\lambda_{i}+\{R R\}_{i}^{a}\right) N_{i}(t)+\sum_{k}(t) q_{i, k^{\prime}}(t) N_{k}(t)+\sum_{k} q_{i, k}(t) N_{k}(t)
$$

where:

$\lambda_{i}=$ decay constant of the nuclide $i$;

$N_{i}(t)=$ concentration of the nuclide $i$;

$\{R R\}_{i}^{a}=$ rate of absorption reaction of the nuclide $i$;

$q_{i k}=$ production terms calculated from the yield of the fission products $i$ by the fission of the nuclide $k$, production fractions, gamma capture and fission reaction rates. 


\subsection{General Sequence of wimsd Code Calculation}

The description of the code can be summarized in four steps: data preparation, central calculation, editing and burnup calculation. First, using the SPECTROX collision theory method [4], the code calculates the spectrum for some spatial regions using its entire energy group library (69 or 172 groups) and uses that spectrum to collapse the cross sections for the number of groups that will be taken to the next step. In the central calculation, the transport equation is solved for a given energy group and for a specific geometry using the DSN or collision probability methods. At the editing stage, corrections are made to the data obtained in the previous step, such as leak correction, effective multiplication factor, buckling that makes the system critical, and rate of reactions. Finally the burn calculation is performed. After completing these steps, the process can be repeated for the initial phase or shut down.

\section{EVALUATED NUCLEAR DATA LIBRARIES}

There are numerous evaluated nuclear data libraries available from various nuclear data centers. National interests and different applications are the two main factors that cause this variety. Countries with strong nuclear programs, such as the US, the European Union, Japan, Russia and China, develop their own general purpose libraries to maintain assessment expertise and ensure technological independence. The main evaluated nuclear data libraries are maintained by the following countries:

1. USA - ENDF / B-VII.1, launched in 2011;

2. Europe - JEFF-3.1, launched in 2005, JEF-2.2, launched in 1992;

3. Japan - JENDL-3.3, launched in 2002, JENDL-4.0, launched in 2010;

4. Russia - BROND-2.2, launched in 1992; BROND-3 has not yet been completed, is partially available in selected ROSFOND assessments, which was launched in 2008;

5. China - CENDL-2, launched in 1991; CENDL-3 was developed, but not internationally released; Development of CENDL-4 is in progress.

During the first decade of the 21st century, three nuclear data libraries evaluated (ENDF / B, JEFF and JENDL) were continually updated and improved. The following libraries will be used in this 
work: IAEA, ENDFB-VII.1, JENDL3.2, JEFF3.1 and JEF2.2, for 69 energy groups and formatted by WLUP [2].

\section{RESULTS AND DISCUSSION}

In order to simulate burning using the WIMSD-5B code, it was considered the MTR-IAEA research reactor of the benchmark problem conceived by the IAEA [6]. This reactor has an active core (height) of $60 \mathrm{~cm}$, each fuel element $(\mathrm{FE})$ has lateral dimensions of $7.7 \mathrm{~cm} \times 8.1 \mathrm{~cm}$. It is a pool-type reactor, its fuel is composed of uranium dispersed in Aluminium (UAlx - Al) and power of $10 \mathrm{MW}$. In the reactor core, there are 23 plates of FE and 21 plates of control/safety element (CSE), where 17 are identical to the FE and the others consisting of pure Al.

As mentioned earlier, the input data of the wimsd- $5 \mathrm{~b}$ code are related to the geometry and material composition of the reactor core.

\subsection{Determination of the MTR-IAEA Equivalent Cell}

The core of the MTR-IAEA reactor is heterogeneous, and one can identify a repeating geometric shape forming the active part of the nucleus. Considering a FE of the MTR-IAEA reactor, with its geometry and material composition shown in Figure 1 and Table 1, it is possible to associate with the FE an equivalent cell which is composed of four regions, as shown in Figure 2: region 1, representing the fuel or, also called crumb; the region 2, representing the coating of the fuel; region 3 representing the refrigerant and moderator and region 4 called the extra region, containing the inert edges of $\mathrm{Al}$ and excess water with the respective atomic densities of each region, Table 2 [7]. 
Figure 1: Cross section of the fuel element of the MTR-IAEA research reactor (units in $\mathrm{cm}$ ).



Table 1: Dimensions and characteristics of the fuel element of the research reactor - MTR-IAEA.

\begin{tabular}{|c|}
\hline Fuel Type $-\mathrm{UAl}_{\mathrm{x}}-\mathrm{Al}$ \\
\hline $72 \mathrm{w} / \mathrm{o}\left(72 \%\right.$ by weight) of Uranium in the $\mathrm{UAl} \mathrm{I}_{\mathrm{x}}-\mathrm{Al}$ \\
\hline${ }^{235} \mathrm{U}$ powder content -20 w/o $(20 \%$ by weight) \\
\hline Mass of ${ }^{235} \mathrm{U}$ per EC (23 plates) $-390 \mathrm{~g}$ \\
\hline${ }^{235} \mathrm{U}$ mass per plate $-16.95652 \mathrm{~g}$ \\
\hline It is considered only the ${ }^{235} \mathrm{U}$ and ${ }^{238} \mathrm{U}$ in fresh fuel \\
\hline Dimensions of the Crumb $-6.275 \mathrm{~cm} \times 0.051 \mathrm{~cm} \times 60 \mathrm{~cm}$ \\
\hline
\end{tabular}




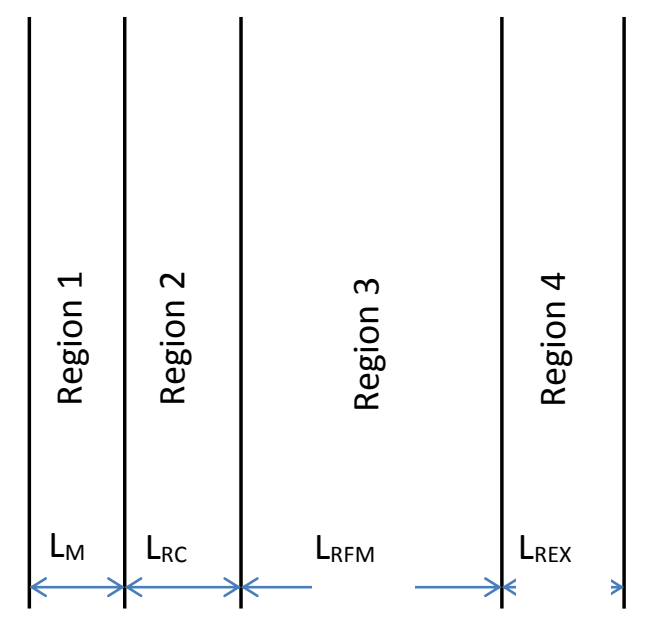

Figure 2: Equivalent cell (non-scaled thickness).

Table 2: Atomic densities and thicknesses of the fuel element equivalent cell of the MTR-IAEA compared to the reference data.

\begin{tabular}{|c|c|c|c|c|c|}
\hline \multirow{2}{*}{ Regions } & \multirow{2}{*}{$\begin{array}{l}\text { Elements } \\
\text { and } \\
\text { Isotopes }\end{array}$} & \multicolumn{2}{|c|}{ Atomic Densities (atoms / barn.cm) } & \multicolumn{2}{|c|}{ Thickness (cm) } \\
\hline & & Reference* $^{*}$ & Calculated & Reference* & Calculated \\
\hline \multirow{3}{*}{$\begin{array}{c}\text { Region 1: } \\
\text { Crumb }\left(\mathbf{U A I _ { x }} \mathbf{A l}\right)\end{array}$} & ${ }^{235} \mathrm{U}$ & $2.2536 \times 10^{-3}$ & $2.26271 \times 10^{-3}$ & \multirow{3}{*}{0.0255} & \multirow{3}{*}{0.0255} \\
\hline & ${ }^{238} \mathrm{U}$ & $8.9005 \times 10^{-3}$ & $8.93652 \times 10^{-3}$ & & \\
\hline & $\mathrm{Al}$ & $3.8171 \times 10^{-2}$ & $3.83265 \times 10^{-2}$ & & \\
\hline $\begin{array}{c}\text { Region 2: } \\
\text { Coating }\end{array}$ & $\mathrm{Al}$ & $6.0260 \times 10^{-2}$ & $6.02439 \times 10^{-2}$ & 0.038 & 0.038 \\
\hline \multirow{2}{*}{$\begin{array}{l}\text { Region 3: } \\
\text { 1/2 Water } \\
\text { Channel }\end{array}$} & $\mathrm{H}$ & $6.6956 \times 10^{-2}$ & $6.66739 \times 10^{-2}$ & \multirow{2}{*}{0.1115} & \multirow{2}{*}{0.1115} \\
\hline & $\mathrm{O}$ & $3.3428 \times 10^{-2}$ & $3.33695 \times 10^{-2}$ & & \\
\hline \multirow{3}{*}{$\begin{array}{l}\text { Region 4: Inert } \\
\text { Edges of Al and } \\
\text { Excess Water }\end{array}$} & $\mathrm{Al}$ & \multirow{3}{*}{$\begin{array}{l}\text { no values } \\
\text { available for } \\
\text { comparison }\end{array}$} & $4.60492 \times 10^{-2}$ & \multirow{3}{*}{0.0402} & \multirow{3}{*}{0.0397} \\
\hline & $\mathrm{H}$ & & $1.57441 \times 10^{-2}$ & & \\
\hline & $\mathrm{O}$ & & $7.87207 \times 10^{-3}$ & & \\
\hline
\end{tabular}

$(*)$ Source: [6]. 


\subsection{Nuclear Data Libraries Evaluated Used}

The other part of the "input" of the wimsd-5b code is formed by the nuclear data library evaluated. For the simulations with the wimsd-5b code, the following nuclear data libraries were used: IAEA, ENDFB-VII.1, JENDL3.2, JEFF3.1 and JEF2.2, for 69 energy groups and formatted by WLUP.

For the IAEA, JENDL3.2, JEFF3.1 and JEF2.2 libraries, the wimsd-5b code in the burnup simulations provides the concentrations of 78 nuclides whereas for the library ENDFB-VII.1, it provides the concentrations of 89 nuclides. For comparison purposes, the concentrations of the 78 nuclides corresponding to all libraries were considered.

\subsection{Burn Simulation and Analysis}

The burnup was simulated over a period of 400 days, which corresponds to a $50 \%$ reduction in the initial ${ }^{235} \mathrm{U}$ concentration. The variations during the burning of the concentrations of some nuclides for the five nuclear data libraries evaluated were plotted in graphs and can be consulted in Figure 3. It can be seen that at the end of the simulation of the burning, in 400 days, the concentrations obtained using the five nuclear data libraries evaluated do not differ in most cases. However, not all libraries produced similar results in the following related cases: ${ }^{242} \mathrm{Cm},{ }^{243} \mathrm{Cm},{ }^{160} \mathrm{Dy},{ }^{161} \mathrm{Dy},{ }^{162} \mathrm{Dy}$, ${ }^{162} \mathrm{Dy},{ }^{165} \mathrm{Ho},{ }^{166} \mathrm{Er},{ }^{167} \mathrm{Er},{ }^{109} \mathrm{Ah},{ }^{127} \mathrm{Te},{ }^{127} \mathrm{I},{ }^{152} \mathrm{Eu}$ and ${ }^{242} \mathrm{Am}$.

When considering the relative percentage absolute deviation between the concentrations found for each nuclear data library, it was found that erbium, which is an element used as burnable poison, showed high deviations [8]. 

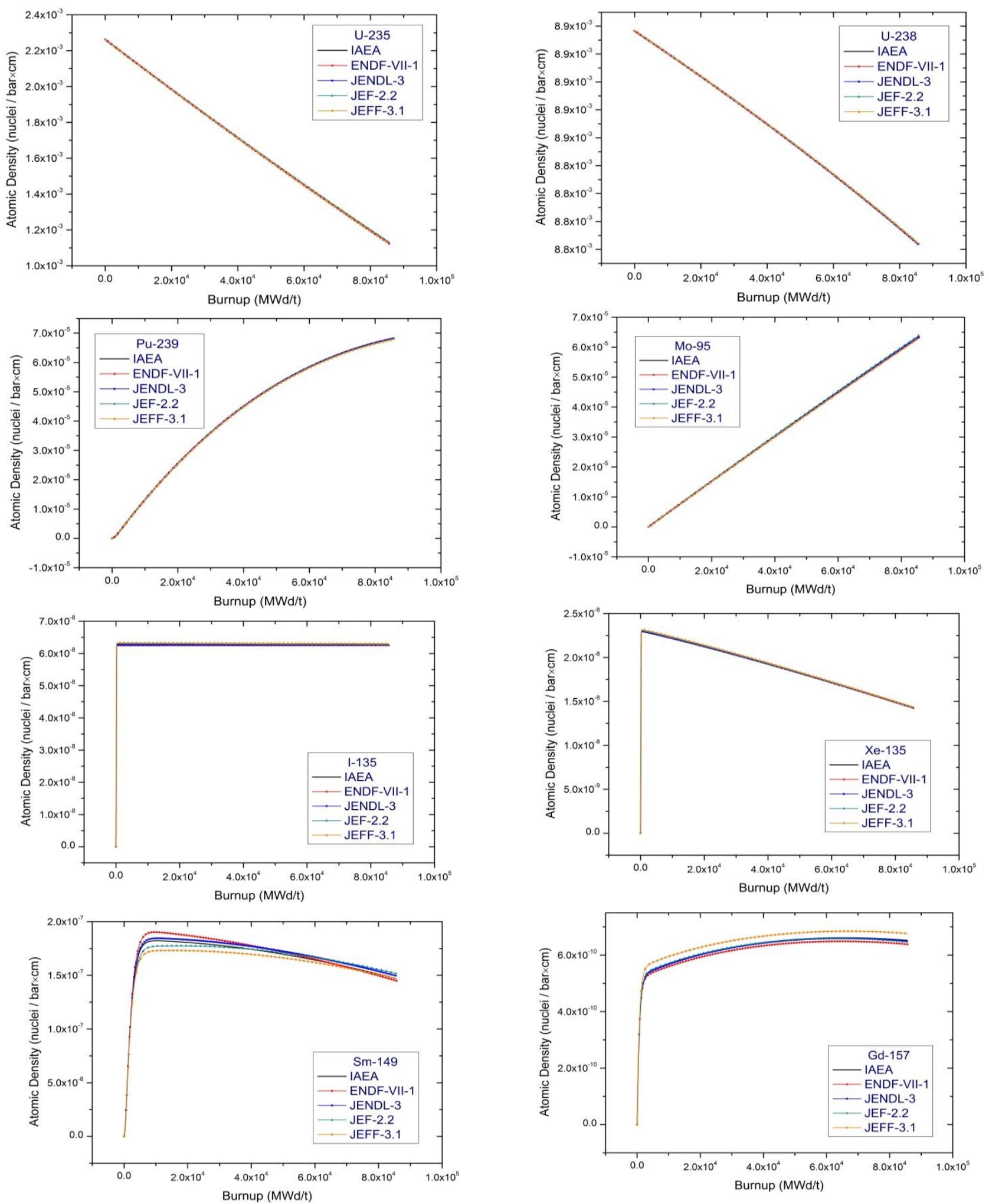

Figure 3: Variations during the burnup of the concentrations of some nuclides for the five nuclear data libraries evaluated. 
It is also important to point out the large variations in the concentrations in the first burnup steps (period few hours) in all the libraries and verified in the following cases: ${ }^{239} \mathrm{~Np},{ }^{157} \mathrm{Gd},{ }^{105} \mathrm{Rh},{ }^{113} \mathrm{Cd}$, ${ }^{135} \mathrm{I},{ }^{135} \mathrm{Xe},{ }^{149} \mathrm{MW},{ }^{149} \mathrm{Sm},{ }^{151} \mathrm{Sm}$ and ${ }^{237} \mathrm{U} \mathrm{PPF}$.

In addition to the variations of the nuclide concentrations, the results of the burnup simulations with the code wimsd-5b, the variation of the infinite multiplication factor, $k_{\infty}$, and the following nuclear parameters condensed for two energy groups were also obtained: diffusion coefficients, $D_{g}$; absortion cross section, $\Sigma_{a g}$; removal cross section, $\Sigma_{r g}$; and the mean number of fission neutrons multiplied by the fission cross section, $v \Sigma_{f g}$.

In Figure $4 \mathrm{a}$ the plot of the $k_{\infty}$ variation as a function of the burn for each nuclear data library is shown and compared to the result obtained with the EPRI-CELL code [6], which was used with the library ENDFB- IV. In this figure the graph was plotted with only a few points. In Figure $4 \mathrm{~b}$ the graphic of the $k_{\infty}$ variation as a function of burnup for each nuclear data library is shown in all burnup steps (400 days). Figure 5a shows the graph plots of the nuclear group variations of the fast group, while Figure $5 \mathrm{~b}$ shows the plots of the graphs of the variations of the nuclear parameters of the thermal group.

(a)



(b)

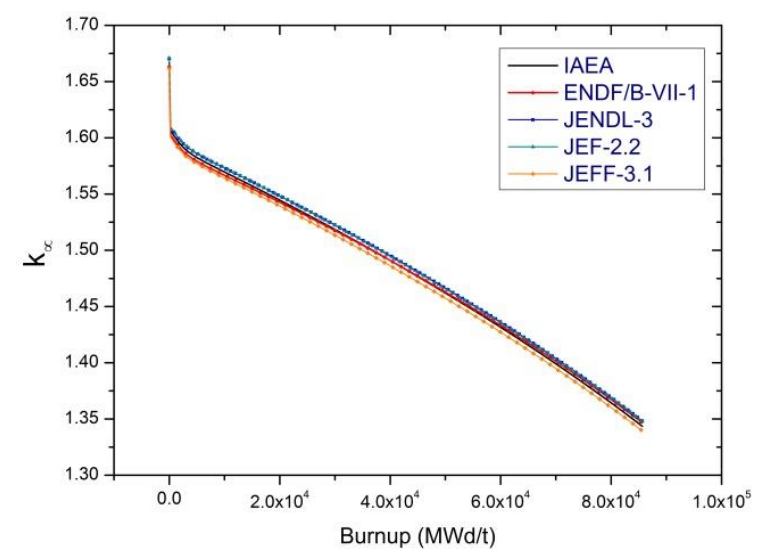

Figure 4: Variation of the infinite multiplication factor.

(a) Comparison with code EPRI-CELL; (b) For all burnup steps. 
(a)

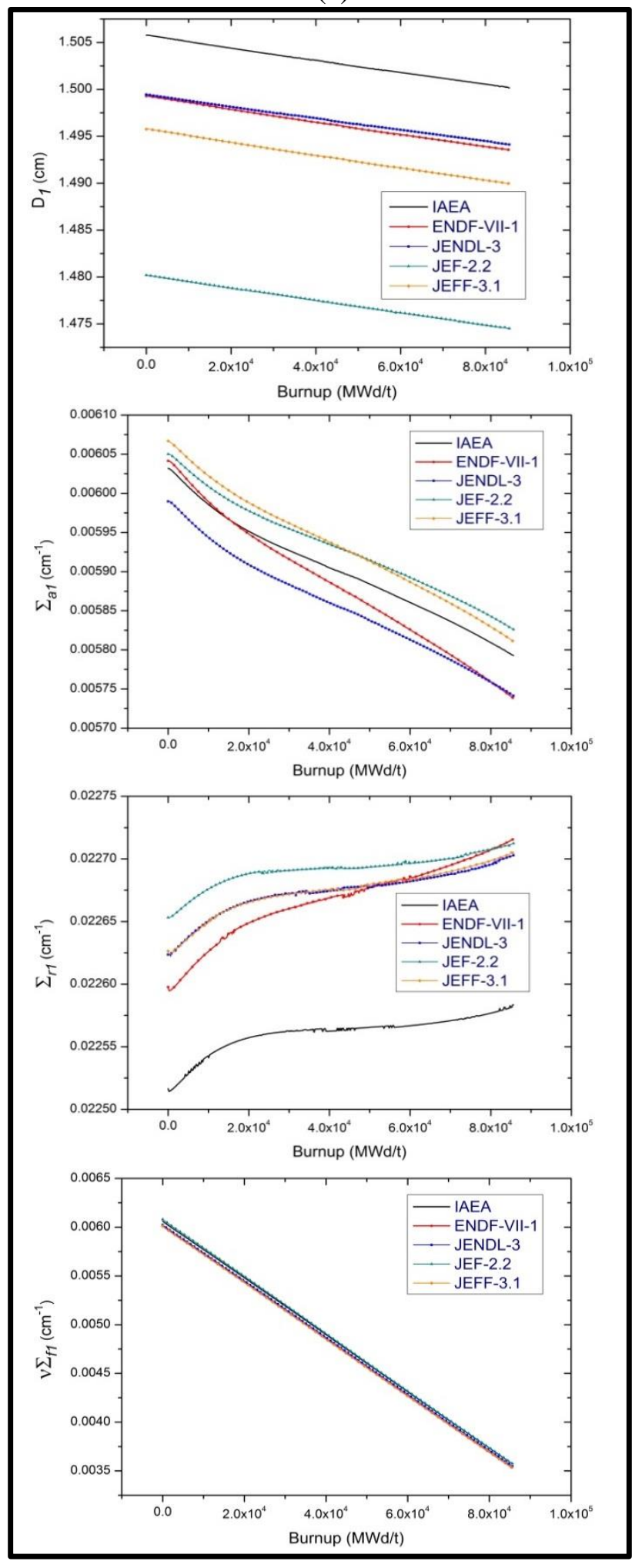

(b)
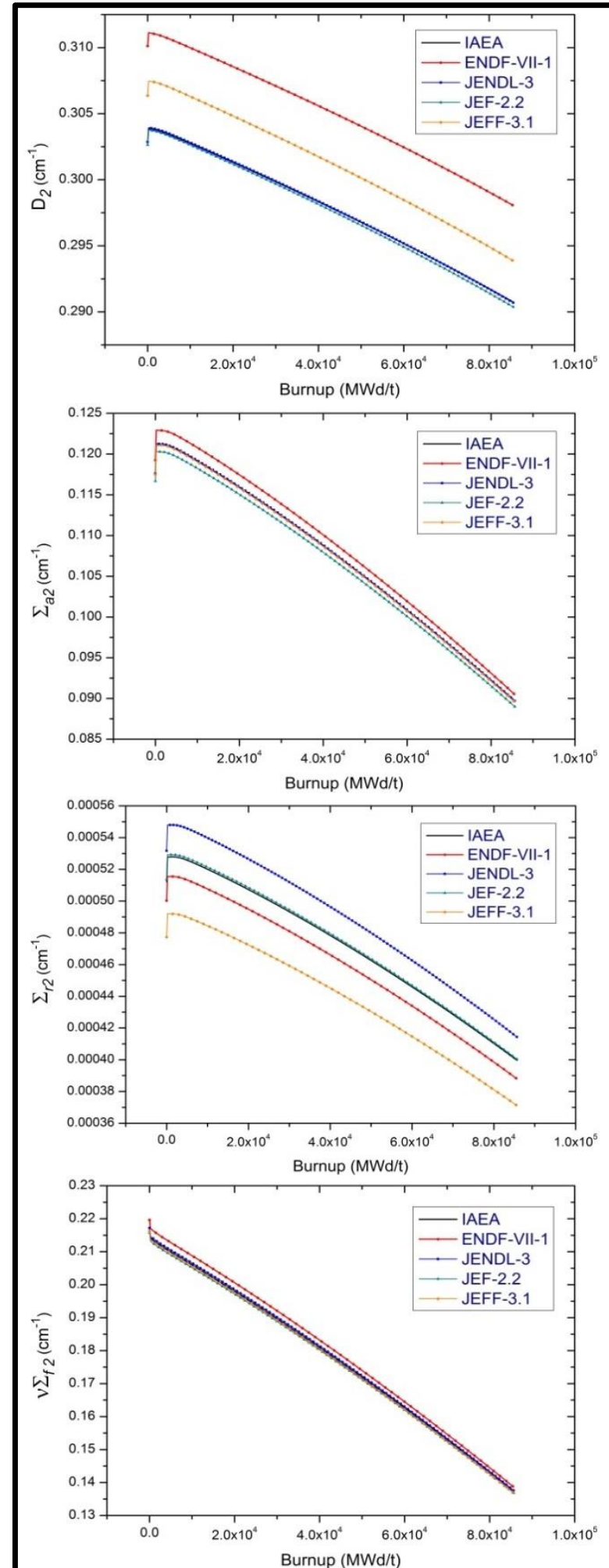

Figure 5: Variation of nuclear parameters. (a) Fast Group; (b) Thermal Group. 
It is seen that the variation of $k_{\infty}$, Figure 4 , is similar for each adopted library, and the same can be affirmed for $v \Sigma_{f g}$ in the two energy groups. However, the parameters $D_{g}, \Sigma_{a g}$ and $\Sigma_{r g}$ showed an offset in the Figure 5 according to the library used. It is also observed that in the graph of Figure 4 the $k_{\infty}$ varies accentuated form in the first burnup steps. The same can be observed in the thermal parameters of the thermal group.

These strong variations are directly related to the large increases in the concentrations of ${ }^{135} \mathrm{Xe}$ and ${ }^{149} \mathrm{Sm}$, Figure $3 .{ }^{135} \mathrm{Xe}$ is the main fission product that affects reactor operation due to its high absorption cross section, in the amount of $2.65 \times 10^{6}$ barn. This isotope can be produced directly from the fission and also from the decay of other fission products. ${ }^{149} \mathrm{Sm}$ is another fission product of high absorption cross section, 41,000 barns.

\section{CONCLUSIONS}

It was observed that in most cases the concentrations of nuclides presented practically the same result independently of the nuclear data library used.

The variation of the infinite multiplication factor was also observed and the variation of the parameter $v \Sigma_{f g}$ in the two energy groups was practically the same regardless of the nuclear data library used.

It is recommended for future work to use the evaluated nuclear data libraries for 192 power groups formatted by WLUP: IAEAGX, ENDFB-VII.1GX, JENDL3.2GX, JEFF3.1GX and JEF2.2GX.

It would also be appropriate to simulate the global calculations of the nucleus by solving the equation of neutron transport or diffusion using the homogenized nuclear parameters that were obtained for each of the nuclear data libraries evaluated and to verify how the neutron flux behaves in relation to each of the libraries. 


\section{ACKNOWLEDGMENT}

The authors are grateful for the support given by CAPES, Coordenação de Aperfeiçoamento de Pessoal de Nível Superior, through the scholarship granted.

\section{REFERENCES}

[1] KULIKOWSKA, T. Reactors Lattice Codes, Workshop on Nuclear Data and Nuclear Reactors: Physics, Design and Safety, Trieste, 13 março a 14 de abril 2000. Available at: http://users.ictp.it/ pub_off/lectures/lns005/Number_1/Kulikowska_3.pdf. Last accessed 20 May 2017.

[2] IAEA - INTERNATIONAL ATOMIC ENERGY AGENCY. WIMS-D LIBRARY UPDATE. Vienna, 2007.

[3] SILVA, C.A.M. Desenvolvimento de uma Metodologia para Simulação de Reatores Refrigerados a Gás com Propósito de Transmutação. Doctoral thesis, UFMG, Belo Horizonte, 2009.

[4] LESLIE, D. C. The 'SPECTROX' Method for Thermal Spectra in Lattice Cells. Reactor Science and Technology (Journal of Nuclear Energy Parts A/B), v. 17, p. 293-306, 1963.

[5] CACUCI, D. G., Handbook of Nuclear Engineering, Volume 1, Springer, 2010.

[6] IAEA - INTERNATIONAL ATOMIC ENERGY AGENCY. Research Reactor Core Conversion from the Use of Highly Enriched Uranium to the use of Low Enriched Uranium Fuel, TECDOC-233-IAEA-(1980), Vienna.

[7] Dos SANTOS, N. R., Estimativa da Queima Espacial do Combustível para Reatores Nucleares de Pesquisa. Master's dissertation, IEN, Rio de Janeiro, 2014.

[8] TAVARES, D. Y. S., Cálculo de Célula com Simulação de Queima Usando o Código wimsd5b Considerando Diferentes Bibliotecas de Dados Nucleares. Master's dissertation, IEN, Rio de Janeiro, 2017. 